Research Paper

\title{
The Role of Serum Procalcitonin Levels in Predicting Ascitic Fluid Infection in Hospitalized Cirrhotic and Non-cirrhotic Patients
}

\author{
Yesim Cekin ${ }^{1}$, Ayhan Hilmi Cekin ${ }^{\circledR}{ }^{\bowtie}$, Adil Duman², Ustun Yilmaz ${ }^{3}$, Bayram Yesil³, Basak Oguz Yolcular ${ }^{4}$ \\ 1. Department of Microbiology, Antalya Training and Research Hospital, Antalya, Turkey. \\ 2. Department of Gastroenterology, Antalya Training and Research Hospital, Antalya, Turkey. \\ 3. Department of Internal Medicine, Antalya Training and Research Hospital, Antalya, Turkey. \\ 4. Department of Biostatistics and Medical Informatics, Akdeniz University Faculty of Medicine Antalya, Turkey. \\ $\square$ Corresponding author: Dr.Ayhan Hilmi Cekin, Uluc Mah., 24. Cadde 1164 Sok. Sefik Aker Sitesi B Blok Daire: 10, Konyaalti, Antalya. Phone: +90 53236148 \\ 71 Fax: +90 2422385848 E-mail: ayhancekin@hotmail.com. \\ (C) Ivyspring International Publisher. This is an open-access article distributed under the terms of the Creative Commons License (http://creativecommons.org/ \\ licenses/by-nc-nd/3.0/). Reproduction is permitted for personal, noncommercial use, provided that the article is in whole, unmodified, and properly cited.
}

Received: 2013.02.02; Accepted: 2013.07.29; Published: 20I3.08.20

\begin{abstract}
Objective: To determine the role of serum procalcitonin levels in predicting ascites infection in hospitalized cirrhotic and non-cirrhotic patients.

Methods: A total of $10 \mathrm{I}$ patients (mean age: $63.4 \pm 1.3,66.3 \%$ were males) hospitalized due to cirrhosis $(n=88)$ or malignancy related $(n=13)$ ascites were included in this study. Spontaneous bacterial peritonitis (SBP, 19.8\%), culture-negative SBP (38.6\%), bacterascites $(4.9 \%)$, sterile ascites $(23.8 \%)$ and malign ascites $(12.9 \%)$ groups were compared in terms of procalcitonin levels in predicting ascites infection. Receiver operating characteristic (ROC) curves were used to evaluate the diagnostic performance of procalcitonin levels and predicting outcome of procalcitonin levels was compared with C-reactive protein (CRP).

Results: Culture positivity was determined in $26.7 \%$ of overall population. Serum procalcitonin levels were determined to be significantly higher in patients with positive bacterial culture in ascitic fluid compared to patients without culture positivity (median (min-max): 4.I (0.2-36.4) vs. 0.4 (0.04-15.8), $\mathrm{p}<0.00 \mathrm{I}$ ). Using ROC analysis, a serum procalcitonin level of $<0.61 \mathrm{ng} / \mathrm{mL}$ in SBP (area under curve (AUC): $0.98 \mathrm{I}, \mathrm{Cl} 95 \%$ : 0.000-I.000, $\mathrm{p}<0.00 \mathrm{I}$ ), $<0.225 \mathrm{ng} / \mathrm{mL}$ in culture-negative SBP (AUC: $0.743, \mathrm{Cl} 95 \%$ : $0.619-0.867, \mathrm{p}<0.00 \mathrm{I}$ ), $<0.42 \mathrm{ng} / \mathrm{mL}$ in SBP and culture-negative SBP patients (AUC: $0.824, \mathrm{Cl} 95 \%: 0.732-0.916, \mathrm{p}<0.00 \mathrm{I}$ ), and $<1.12 \mathrm{ng} / \mathrm{mL}$ in bacterascites (AUC: $0.837, \mathrm{Cl}$ 95\%: $0.000-1.000, p=0.019$ ) were determined to accurately rule out the diagnosis of bacterial peritonitis. Predictive power of serum procalcitonin levels in SBP + culture-negative SBP group (AUCs: 0.824 vs 0.622 , $p=0.004$, Fig 4), culture-positive SBP (AUCs: 0.98 I vs $0.777, p=0.006$, Fig 5 ) and (although less powerfull) in culture-negative SBP (AUCs: 0.743 vs $0.543, p=0.02$, Fig 6 ) were found significantly higher than CRP.

Conclusion: According to our findings determination of serum procalcitonin levels seems to provide satisfactory diagnostic accuracy in differentiating bacterial infections in hospitalized patients with liver cirrhosis related ascites.
\end{abstract}

Key words: Procalcitonin; ascitic fluid infection; hospitalized patients; cirrhosis; malignancy; cut-off value.

\section{Introduction}

Cirrhosis holds the first rank among the etiologic factors of ascites followed by malignancy, heart fail- ure, tuberculosis, pancreatic disease, or other miscellaneous causes [1]. The development of ascites in cir- 
rhosis indicates a poor prognosis with mortality of approximately $40 \%$ at 1 year and $50 \%$ at 2 years with increased risk for other complications of liver disease, including refractory ascites, SBP, hyponatremia, or hepatorenal syndrome (HRS) [1].

Classified as spontaneous bacterial peritonitis (SBP) with polymorphnuclear (PMN) count $>250 \mathrm{~mm}^{3}$ and positive ascitic fluid culture without any evidence of external or intraabdominal source of infection [2] or malignancy [3], culture-negative SBP with PMN >250 $\mathrm{mm}^{3}$ and a negative ascitic fluid culture [4], bacterascites with a positive ascitic fluid culture and an ascitic PMN count $<250$ cells $/ \mathrm{mm}^{3}$ [5] and steril ascites with PMN $<250 \mathrm{~mm}^{3}$ and a negative ascitic fluid culture [6], ascitic fluid infections are considered serious complications in cirrhotic patients with a reported incidence of $8-30 \%$ [2] and high morbidity and mortality [7].

Given that $1.5-3.5 \%$ of prevalence in outpatients [8,9] while almost $10 \%$ in hospitalized patients [8], a very high recurrence rate of up to $70 \%$ at 1 year [4] and in-hospital mortality that ranges from $20 \%$ to $40 \%$ $[10,11]$ and even to $78 \%$ [2], early diagnosis of SBP along with prompt initiation of empiric antibiotic therapy have been considered crucial in overall patient's survival [7].

Hence, a diagnostic paracentesis with an appropriate ascitic fluid analysis is considered essential in all patients admitted to hospital with ascites prior to any therapy regardless of whether or not there is clinical suspicion [3] to exclude causes of ascites other than cirrhosis and rule out SBP in cirrhosis [1].

However, despite the use of sensitive methods, ascites culture has been negative in as many as $60 \%$ of patients with clinical manifestations suggestive of SBP and increased ascites neutrophil count [1]. In this regard, given that the crucial role of requiring prompt recognition and treatment, in all the available guidelines, diagnosis has been based on a fixed defined cut-off PMN count in the ascitic fluid with the greatest sensitivity is reached at a cut-off value of 250 $\mathrm{PMN} / \mathrm{mm}^{3}[3,12]$. Although the best specificity has been reported with a cut-off of $500 \mathrm{PMN} / \mathrm{mm}^{3}$ $[13,14]$, the most sensitive cut-off value is used routinely since it is important not to miss a case of SBP [3].

Nonetheless, in the emergency setting, performing ascitic fluid culture examination is time consuming and not always available [17] indicating the need for easy to apply, rapid and reliable markers to predict diagnosis in patients with ascites.

In this regard, based on significantly increased serum levels with the systemic response of the organism to the infection [15], the propeptide of calcitonin with a long half-life of $25-30 \mathrm{~h}$, procalcitonin
$[16,17]$, has been hailed as a novel index of inflammation marker of bacterial infection [15]. Being undetectable in the serum of healthy humans with values $>0.5 \mathrm{ng} / \mathrm{mL}$ were considered abnormal $[16,17]$, procalcitonin has been reported to be superior to C-reactive protein (CRP) in discriminating infectious from other inflammatory diseases such as acute pancreatitis [18], cardiogenic shock [19] and acute transplant rejection $[15,20]$.

Based on its rapid detection within 2 hours or as a recently available bedside test at moderate cost [15], serum procalcitonin determination seems to add some advantages to the traditional cell count for the diagnosis of SBP, especially in the absence of another site of infection, via providing valuable information immediately by a non-invasive diagnostic test in patients [15]. Accordingly, initial interest in its use in SBP [15] was eventually dampened by another study a year later [21] with growing scientific interest in its role in prediction of ascitic fluid infection.

In relation to great risk attributable to infections of the ascitic fluid in patients with ascites [7] that requires appropriate diagnostic studies and prompts administration of therapy [22], the present study was designed to determine the value role of serum procalcitonin levels in predicting ascitic fluid infection in hospitalized cirrhotic and non-cirrhotic patients.

\section{Methods}

\section{Study population}

A total of 143 patients hospitalized due to ascites with data on diagnostic abdominal paracentesis for ascitic fluid analysis and concomitant evaluation of serum procalcitonin levels were included in this study conducted in Department of Gastroenterology at Antalya Training and Research Hospital between January 2011 and July 2012. In this retrospective-cross sectional study for determination of the value role of serum procalcitonin levels in predicting ascites infection in cirrhotic and non-cirrhotic patients, 32 patients were excluded because of clinical infections diagnosed other than ascitic fluid infection. A total of 101 patients (mean age: $63.4 \pm 1.3,66.3 \%$ were males) hospitalized due to cirrhosis related $(n=88)$ or malignancy related $(n=13)$ ascites were included in this study. The study was approved by the clinical research and Ethics Committee of Antalya Training and Research Hospital.

\section{Paracentesis and culture techniques}

Diagnostic paracentesis was carried out at the bedside using a sterile method with a 23-G needle attached to a 20-cc syringe after local anesthesia with lidocaine using a 17-G needle. Immediately after the paracentesis needle and attached syringe were with- 
drawn from the abdomen, the 'skin' needle was removed and replaced with a sterile needle to minimize the risk of skin flora growing in the cultures. Then, aspirated ascitic fluid was collected into ethylenediaminetetraacetic acid tubes and analyzed within $3 \mathrm{~h}$ of aspiration. Ascitic fluid was then centrifuged in the laboratory for $3 \mathrm{~min}$ and analyzed for total proteins and total and differential leukocyte counts. A smear was carried out and stained with Giemsa. Peritoneal fluid collected from patients was cultured via two methods. Initially, 20-mL peritoneal fluid was inoculated in aerobic blood culture bottles (bioMerieux, Durham, NC, USA), respectively. These bottles were then placed into an automated BacT/Alert 3D (bioMerieux) culture system. Bottle incubation and subsequent testing were carried out according to the manufacturer's protocol. The remaining sample was used in conventional culture methods (i.e. inoculating blood agar, MacConkey agar and thioglycollate broth). The conventional agar and broth media were incubated at $35^{\circ} \mathrm{C}$ for up to 3 days before being discarded as negative. Bacterial identification and antimicrobial susceptibility testing were carried out using standard procedures [23].

\section{Classification of patients according to ascitic fluid infection}

The presence of ascitic fluid infection was determined based on white blood cell (WBC) / polymorphonuclear leukocyte (PMNL) counts and the culture positivity in ascitic fluids (AF). Accordingly patients were classified into four groups with respect to ascitic fluid infection including SBP (WBC count $\geq$ $500 / \mathrm{mm}^{3}$ and PMNL $>250 / \mathrm{mm}^{3}$ in AF with a positive bacterial culture), culture-negative SBP (WBC count $\geq$ $500 / \mathrm{mm}^{3}$ and PMNL $>250 / \mathrm{mm}^{3}$ in AF but the culture is negative), bacterascites (WBC count is $<500 / \mathrm{mm}^{3}$ and PMNL $<250 / \mathrm{mm}^{3}$ in AF with a positive bacterial culture) and sterile ascites (WBC count is $<500 / \mathrm{mm}^{3}$ and PMNL $<250 / \mathrm{mm}^{3}$ in AF and the culture is negative). Additionally patients with malign ascites without underlying chronic liver disease composed the fifth group.

Etiology of cirrhosis was recorded in cirrhotic patients with respect to $\mathrm{HBV}, \mathrm{HCV}$, alcoholic, cryptogenic and autoimmune cirrhosis. The severity of cirrhosis was classified on the basis of the Child-Pugh criteria [24], while all of the cirrhotic patients were evaluated for the presence of hepatocellular carcinoma with ultrasonography and serum levels for AFP.

\section{Assessments}

Data on ascitic fluid analysis including WBC count $\left(/ \mathrm{mm}^{3}\right)$, albumin, protein, glucose and lactate dehydrogenase (LDH) in ascitic fluid, blood bio- chemistry including serum levels of albumin, CRP and alpha-feto protein (AFP), sedimentation rate, serum-ascites albumin gradient (SAAG) and serum procalcitonin levels $(\mathrm{ng} / \mathrm{mL})$ were obtained from each patient's medical record.

Procalcitonin level of serum samples which were taken at the same time with the ascite samples were measured via Cobas immunoassay analyser (Roche Diagnostics, Mannheim, Germany) using electrochemiluminescence immunoassay (ECLIA) method (Brahms Diagnostica, Berlin, Germany) with the detection limit of $0.5 \mathrm{ng} / \mathrm{mL}$ and the coefficient of variability of $8 \%$.

SBP, culture-negative SBP, combination group (SBP + culture-negative SBP), bacterascites, sterile and malign ascites groups were compared in terms of procalcitonin levels to determine the value role of procalcitonin levels in predicting ascitic fluid infection. Cut-off values for procalcitonin levels $(\mathrm{ng} / \mathrm{mL})$ ruling out the diagnosis of bacteremia were calculated in each group. Receiver operating characteristics (ROC) curves were plotted for procalcitonin levels for combination group, SBP and culture-negative SBP with CRP to evaluate their abilities to identify ascitic fluid infection in study population. Predicting outcomes of procalcitonin levels were compared with CRP by comparing their area under the curve (AUC).

\section{Statistical analysis}

Mann-Whitney $U$ test was used for comparison of quantitative variables with non-normal distribution and performed using computer software (SPSS version 13.0, SPSS Inc. Chicago, IL, USA). ROC curves and decision plots were used to choose significant parameters and determine optimum cut-off values by maximizing sensitivity and specificity. Data are expressed as $\mathrm{n}(\%)$, mean \pm standard error of mean (SEM), median (minimum-maximum) or area under the curve (AUC, 95\% confidence interval (CI)), where appropriate. $\mathrm{p}<0.05$ was considered statistically significant.

\section{Results}

\section{Patient demographics and classification ac- cording to classification of ascites}

Of 101 patients (age: $63.4 \pm 1.3,66.3 \%$ were males) hospitalized with ascites, cirrhosis was the underlying reason in $88(87.1 \%)$ patients including SBP $(19.8 \%)$, culture-negative SBP (38.6\%), bacterascites $(4.9 \%)$ and sterile ascites $(23.8 \%)$, while the ascites was due to malignancy in $13(12.9 \%)$ patients. HBV related cirrhosis $(26.7 \%)$; HCV related cirrhosis $(21.8 \%)$ and alcoholic cirrhosis $(19.8 \%)$ were the most common cirrhosis types (Table 1 ). 


\section{Ascitic fluid analysis}

Ascitic fluid analysis revealed WBC count (cell/mm3) of $6035 \pm 1738.4$ in SBP, $2041 \pm 450.4$ in culture-negative SBP, $368 \pm 43.1$ in bacterascites, $243 \pm$ 23.8 in sterile ascites while $2685 \pm 417.0$ in malign ascites (Table 1).

Serum-ascites albumin gradient was $1.6 \pm 0.1$ in culture-positive SBP and culture-negative SBP, $1.7 \pm$ 0.1 in bacterascites and sterile ascites while $1.0 \pm 0.1$ in malign ascites (Table 1).

Determined in all of the patients with SBP and bacterascites and $15.4 \%$ of patients with malign ascites, culture positivity was determined in $26.7 \%$ of overall population (Table 1). In our culture positive patients $(\mathrm{n}=27), \mathrm{ESBL}$ positive E. Coli was responsible microorganism in $10(37.0 \%)$ patients, coagulase negative staphylococci in 6 patients $(22.2 \%)$, enterococci in 3 patients $(11.1 \%)$ while ESBL negative E.coli in 2 patients $(7.4 \%)$.

\section{Procalcitonin levels with respect to classifica- tion of ascites}

Serum procalcitonin levels were determined to be significantly higher in patients with positive bacterial culture in ascitic fluid compared to patients without culture positivity $(4.1 \quad(0.2-36.4)$ vs. 0.4 (0.04-15.8), $\mathrm{p}<0.001)$. Procalcitonin levels in SBP (4.7 (0.6-36.4), $\quad \mathrm{p}<0.001), \quad$ culture-negative SBP $\quad(0.7$ (0.04-15.8), $\mathrm{p}<0.001)$ and bacterascites (1.88 (0.2-6.5), $\mathrm{p}=0.019)$ were significantly higher than procalcitonin levels in sterile ascites (0.3 (0.1-3.7)). Procalcitonin levels in malign ascites $(0.4(0.02-1.12), \mathrm{p}=0.513)$ was similar to sterile ascites while significantly lower than $\mathrm{SBP}(\mathrm{p}<0.001$, Table 2).

Table I. Patient demographics and ascitic fluid analysis with respect to classification of ascites

\begin{tabular}{|c|c|c|c|c|c|c|}
\hline & \multirow[t]{2}{*}{ Total } & \multicolumn{5}{|c|}{ Classification of ascites } \\
\hline & & $\mathrm{SBP}^{1}$ & Culture negative $\mathrm{SBP}^{2}$ & Bacterascites $^{3}$ & Sterile ascites ${ }^{4}$ & Malign ascites $^{5}$ \\
\hline Age (years) Mean(SEM) & $63.4(1.3)$ & $64.2(2.8)$ & $65.3(1.8)$ & $61.6(4.9)$ & $59.5(3.1)$ & $64.5(4.1)$ \\
\hline Gender & $\mathrm{n}(\%)$ & & & & & \\
\hline Female & $34(33.7)$ & $8(40.0)$ & $9(23.1)$ & $1(20.0)$ & $5(20.8)$ & $11(84.6)$ \\
\hline Male & $67(66.3)$ & $12(60.0)$ & $30(76.9)$ & $4(80.0)$ & $19(79.2)$ & $2(15.4)$ \\
\hline Total & 101(100.0) & $20(19.8)$ & $39(38.6)$ & $5(4.9)$ & $24(23.8)$ & 13(12.9) \\
\hline Etiology of ascites & $\mathrm{n}(\%)$ & & & & & \\
\hline HBV related cirrhosis & $27(26.7)$ & $5(25.0)$ & $13(33.3)$ & $2(40.0)$ & $7(29.2)$ & - \\
\hline HCV related cirrhosis & $22(21.8)$ & $7(35.0)$ & $8(20.5)$ & $1(20.0)$ & $6(25.0)$ & - \\
\hline Alcoholic cirrhosis & 20(19.8) & $5(20.0)$ & $7(19.9)$ & $1(20.0)$ & $7(29.2)$ & - \\
\hline Cryptogenic cirrhosis & $17(16.8)$ & $3(15.0)$ & $11(28.2)$ & $1(20.0)$ & $2(8.3)$ & - \\
\hline Autoimmune cirrhosis & $2(2.0)$ & $0(0.0)$ & $0(0.0)$ & $0(0.0)$ & $2(8.3)$ & - \\
\hline Malignancy & - & - & - & - & - & $13(12.9)$ \\
\hline Child Score Mean(SEM) & $9.7(0.4)$ & $11.2(0.7)$ & $10.9(0.3)$ & $12.0(0.3)$ & $11.3(0.2)$ & - \\
\hline Ascitic fluid analysis & Mean(SEM) & & & & & \\
\hline WBC (cell/mm³) & $2400.8(431.2)$ & $6035(1738.4)$ & $2041(450.4)$ & $368(43.1)$ & $243(23.8)$ & $2685(417.0)$ \\
\hline Albumin & $1.0(0.1)$ & $0.8(0.1)$ & $1.0(0.1)$ & $0.7(0.2)$ & $0.7(0.1)$ & $2.3(0.2)$ \\
\hline SAAG & $1.6(0.1)$ & $1.6(0.1)$ & $1.6(0.1)$ & $1.7(0.1)$ & $1.7(0.1)$ & $1.0(0.1)$ \\
\hline Glucose & $104.6(4.2)$ & 111.1(12.4) & $102.9(5.5)$ & $122.8(16.7)$ & $105.9(10.1)$ & $92.9(7.7)$ \\
\hline LDH & $201.9(22.9)$ & $2202.4(31.2)$ & $181.9(39.5)$ & $88.0(14.7)$ & $97.7(16.2)$ & $549.2(84.4)$ \\
\hline Protein & $1.8(0.1)$ & $1.6(0.1)$ & $1.7(0.1)$ & $1.6(0.2)$ & $1.7(0.1)$ & $3.0(0.3)$ \\
\hline Positive culture $\quad n(\%)$ & $27(26.7)$ & $20(100.0)$ & $0(0.0)$ & $5(100.0)$ & $0(0.0)$ & $2(15.4)$ \\
\hline Serum analysis & Mean(SEM) & & & & & \\
\hline Albumin & $2.6(0.1)$ & $2.4(0.1)$ & $2.5(0.1)$ & $2.5(0.1)$ & $2.4(0.1)$ & $3.4(0.1)$ \\
\hline Sedimentation rate & $39.7(2.2)$ & $35.0(4.9)$ & $36.4(3.0)$ & $32.4(5.6)$ & $35.5(4.4)$ & $68.7(4.7)$ \\
\hline CRP & $38.9(4.9)$ & 67.4(17.2) & $31.7(6.3)$ & $22.4(5.7)$ & $20.0(3.4)$ & $54.2(13.9)$ \\
\hline $\mathrm{AFP}$ & $77.5(42.7)$ & $6.4(1.2)$ & $163.1(107.0)$ & $2.5(0.4)$ & $53.2(42.2)$ & $2.3(0.3)$ \\
\hline
\end{tabular}

1SBP: Spontaneous bacterial peritonitis (WBC count $\geq 500 / \mathrm{mm}^{3}$ and PMNL $>250 / \mathrm{mm}^{3}$ in AF with a positive bacterial culture), ${ }^{2} \mathrm{WBC}$ count $\geq 500 / \mathrm{mm}^{3}$ and $\mathrm{PMNL}$

$>250 / \mathrm{mm}^{3}$ in AF but the culture is negative, ${ }^{3} \mathrm{WBC}$ count is $<500 / \mathrm{mm}^{3}$ and PMNL $<250 / \mathrm{mm}^{3}$ in AF with a positive bacterial culture, ${ }^{4} \mathrm{WBC}$ count is $<500 / \mathrm{mm}^{3}$ and $\mathrm{PMNL}$ $<250 / \mathrm{mm}^{3}$ in AF and the culture is negative, ${ }^{5}$ patients without chronic liver disease, SAAG: Serum-ascites albumin gradient, LDH: lactate dehydrogenase, CRP: C-reactive protein, AFP: alpha-fetoprotein. 
Table 2. Comparison of ascites types with respect to serum procalcitonin level ( $\mathrm{ng} / \mathrm{mL})$.

\begin{tabular}{lll}
\hline & Serum procalcitonin level $(\mathrm{ng} / \mathrm{mL})$ & $\mathrm{p} \mathrm{value}^{*}$ \\
\hline AF culture positivity & Median(min-max) & $<0.001$ \\
Absent & $0.4(0.04-15.8)$ & \\
Present & $4.1(0.2-36.4)$ & \\
Classification of ascites & Median(min-max) & $<0.001$ vs. sterile ascites \\
Culture-positive SBP ${ }^{1}$ & $4.7(0.6-36.4)$ & 0.001 vs. sterile ascites \\
Culture-negative SBP ${ }^{2}$ & $0.7(0.04-15.8)$ & $<0.001$ vs. sterile ascites \\
Total SBP & $1.01(0.04-36.4)$ & 0.019 vs. sterile ascites \\
Bacterascites $^{3}$ & $1.9(0.2-6.5)$ & \\
Sterile ascites $^{4}$ & $0.3(0.1-3.7)$ & 0.513 vs. sterile ascites $<0.001$ vs. culture-positive SBP \\
Malign ascites $^{5}$ & $0.4(0.02-1.12)$ & .
\end{tabular}

AF: ascitic fluid, ${ }^{*}$ Mann-Whitney $\mathrm{U}$ test, ${ }^{1} \mathrm{WBC}$ count $\geq 500 / \mathrm{mm}^{3}$ and PMNL $>250 / \mathrm{mm}^{3}$ in AF with a positive bacterial culture), ${ }^{2} \mathrm{WBC}$ count $\geq 500 / \mathrm{mm}^{3}$ and PMNL

$>250 / \mathrm{mm}^{3}$ in AF but the culture is negative, ${ }^{3} \mathrm{WBC}$ count is $<500 / \mathrm{mm}^{3}$ and PMNL $<250 / \mathrm{mm}^{3}$ in AF with a positive bacterial culture, ${ }^{4} \mathrm{WBC}$ count is $<500 / \mathrm{mm}^{3}$ and PMNL $<250 / \mathrm{mm}^{3}$ in $\mathrm{AF}$ and the culture is negative, ${ }^{5}$ patients without chronic liver disease.

\section{Cut-off values for procalcitonin with respect to classification of ascites}

For SBP group, the cut-off value for procalcitonin was $0.61 \mathrm{ng} / \mathrm{mL}$ with sensitivity $100 \%$, specificity 92\%. A serum procalcitonin level of $<0.61 \mathrm{ng} / \mathrm{mL}$ (AUC: 0.981, CI 95\%: 0.000-1.000, p<0.001) was determined to accurately rule out the diagnosis of bacterial infection (Fig 1).

For culture-negative SBP group, the cut-off value for procalcitonin was $0.225 \mathrm{ng} / \mathrm{mL}$ with sensitivity $82 \%$, specificity $50 \%$. A serum procalcitonin level of $<0.225 \mathrm{ng} / \mathrm{mL}$ (AUC: 0.743, CI 95\%: 0.619-0.867, $\mathrm{p}<0.001)$ was determined to accurately rule out the diagnosis of bacterial infection (Fig 2).

For bacterascites group, the cut-off value for procalcitonin was $1.12 \mathrm{ng} / \mathrm{mL}$ with sensitivity $80 \%$, specificity $96 \%$. A serum procalcitonin level of $<1.12$ $\mathrm{ng} / \mathrm{mL}$ (AUC: 0.837, CI 95\%: 0.000-1.000, $\mathrm{p}=0.019$ ) was determined to accurately rule out the diagnosis of bacterial infection (Fig 3).

For combination group, the cut-off value for procalcitonin was $0.42 \mathrm{ng} / \mathrm{ml}$ with sensitivity $78 \%$, specificity $75 \%$. A serum procalcitonin level of $<0.42$ ng/mL (AUC: 0.824, CI 95\%: 0.732-0.916, p<0.001) was determined to accurately rule out the diagnosis of bacterial infection.

\section{Comparison of procalcitonin with CRP with respect to classification of ascites}

To evaluate performance measures of procalcitonin levels in predicting bacterial infections, AUCs of procalcitonin levels and CRP were compared in combination group, SBP and culture-negative SBP groups. From the results of ROC analysis, AUCs of procalcitonin levels in combination group (0.824 vs 0.622 , $\mathrm{p}=0.004$, Fig 4), SBP (0.981 vs 0.777, $\mathrm{p}=0.006$, Fig 5) and culture-negative SBP (0.743 vs $0.543, \mathrm{p}=0.02$, Fig 6$)$ were found significantly larger than CRP.

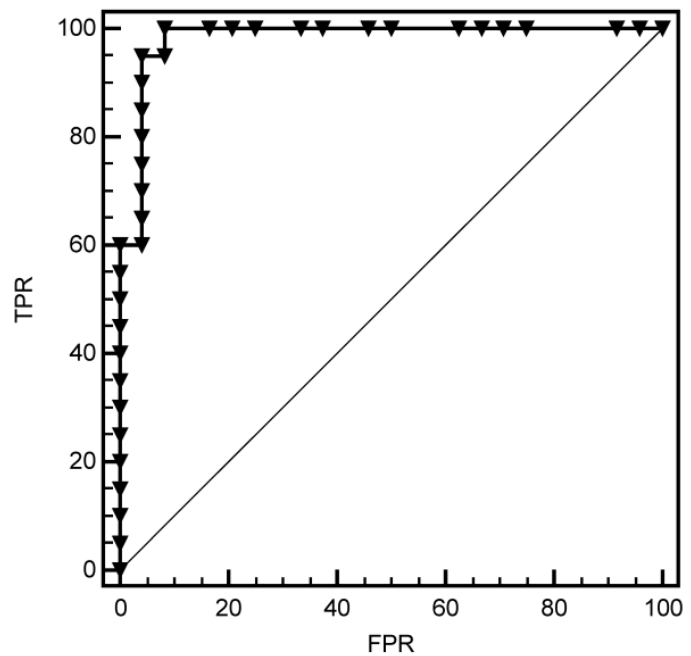

Fig I. Cut-off value for procalcitonin in SBP group. FPR=False Positive Rate (I- Specificity), TPR= True Positive Rate (Sensitivity).

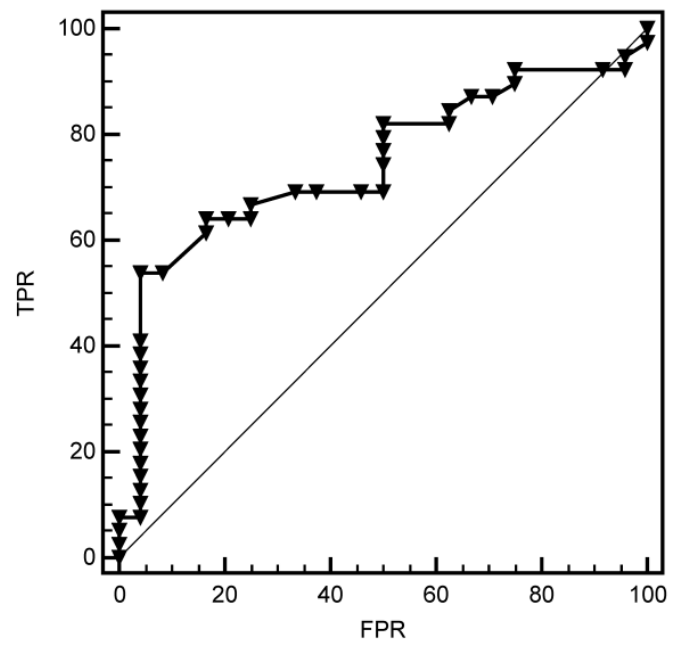

Fig 2. Cut-off value for procalcitonin in the culture-negative SBP group. FPR=False Positive Rate (I-Specificity), TPR= True Positive Rate (Sensitivity). 


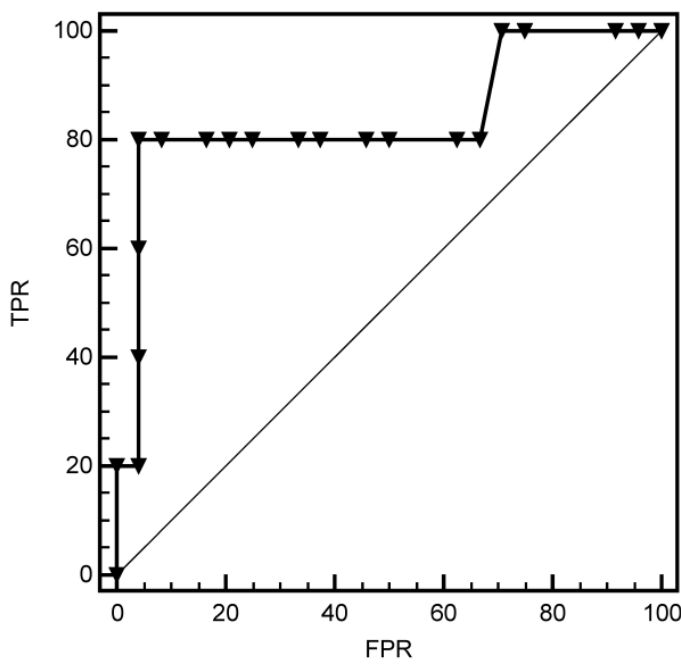

Fig 3. Cut-off value for procalcitonin in bacterascites group. $F P R=F a l s e$ Positive Rate (I-Specificity), TPR= True Positive Rate (Sensitivity).

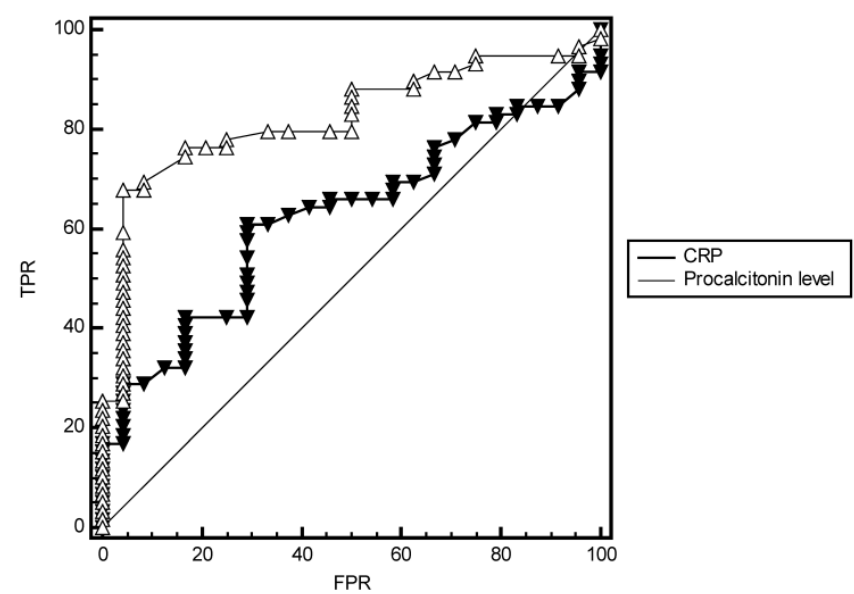

Fig 4. Comparison of ROC curves of Procalcitonin levels and CRP in diagnosis of combination group (SBP + culture-negative SBP) and sterile patients. FPR=False Positive Rate ( $\mathrm{I}$ - Specificity), TPR= True Positive Rate (Sensitivity).

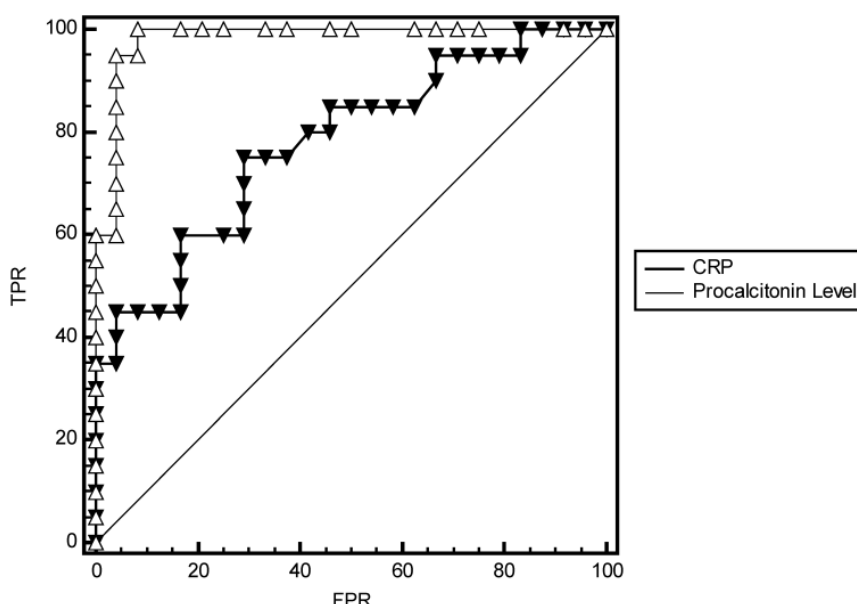

Fig 5. Comparison of ROC curves of Procalcitonin levels and CRP in diagnosis of SBP and sterile patients. FPR=False Positive Rate (I- Specificity), TPR= True Positive Rate (Sensitivity).

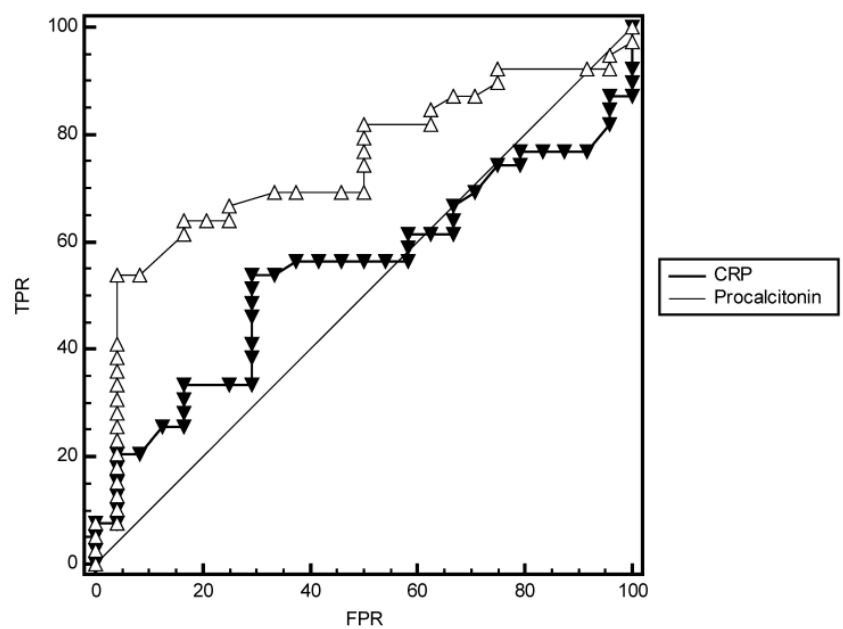

Fig 6. Comparison of ROC curves of Procalcitonin levels and CRP in diagnosis of culture-negative SBP and sterile patients. FPR=False Positive Rate (I-Specificity), TPR= True Positive Rate (Sensitivity).

\section{Discussion}

Owing to frequent hospitalization requiring extremely complex and labor-intensive care as well as appreciable morbidity and mortality associated with SBP, there should always be a high index of suspicion for it while selecting the appropriate diagnostic studies and prompt administration of therapy are the mainstay of successful management [22].

Compatible with their ability to translocate into mesenteric lymph nodes; Escherichia coli, Klebsiella pneumoniae and other Enterobacteriaceae have been reported as the species most frequently cause SBP via bacterial translocation [3]. Accordingly, in our culture positive patients $(n=27)$, while more compatible with the community-acquired infections rather than nosocomial infections with the predominance of Gram negative over Gram positive bacteria [25], ESBL positive E. Coli was the most commonly cultured microorganism $(37.0 \%)$ followed by coagulase negative staphylococci $(22.2 \%)$, enterococci $(11.1 \%)$ and ESBL negative E.coli $(7.4 \%)$.

Studies on the incidence of ascitic fluid infection in cirrhosis revealed highly varying results reported to be $27.7 \%$ [26] in one study while, ranged from $50-71 \%$ in others $[27,28]$.

Accordingly, in contrast to other markers found to be indicative of SBP including ascitic $\mathrm{pH}$, lactate dehydrogenase, lactate none of which was considered sufficiently predictive or discriminative with possible risk of increase also in malignancy-related ascites [3], serum procalcitonin levels seem to be significant predictor of SBP with high sensitivity and sensitivity as well as of culture-negative SBP and bacterascites in our study population with an increase obtained in 
procalcitonin levels specific to cirrhosis related but not to malignancy related ascites.

The production of procalcitonin, unlike that of CRP, was reported to be elevated only in response to bacterial infection but not to noninfectious inflammation or nonbacterial infection [29]. Accordingly, our results have shown that procalcitonin was significantly increased in serum of patients with cirrhosis related ascites but most markedly in culture-positive SBP with a high sensitivity and specificity for a cut off value of 0.61 . Additionally, our results have shown that procalcitonin was better than CRP in predicting ascetic fluid infection in cirrhotic patients $(p<0.004)$. Similarly, in a past study by Viallon et al. serum levels of procalcitonin was reported to be one of the best markers for the diagnosis of SBP, with a cut-off value of $0.75 \mathrm{ng} / \mathrm{ml}$, sensitivity of $95 \%$ and specificity of 98 $\%$ [15].

In our cirrhotic patients, the area under the ROC curve for procalcitonin in predicting culture-positive SBP (0.981), culture-negative SBP (0.743) and bacterascites $(0.837)$ are in accordance with the diagnostic capacity of procalcitonin reported in the cirrhotic population (AUC: 0.68-0.89) [30]. Given that the cut-off value proposed for procalcitonin in cirrhosis is identical to that used in the general population $(0.5$ $\mathrm{ng} / \mathrm{ml}$ ) [30], cut-off values for procalcitonin in cirrhotic patients with culture-positive SBP (0.61 $\mathrm{ng} / \mathrm{mL})$, culture-negative SBP $(0.225 \mathrm{ng} / \mathrm{mL})$ and bacterascites $(1.12 \mathrm{ng} / \mathrm{mL})$ in our study population seem to indicate the predictive value of higher procalcitonin values in case of ascites infection with culture positivity in the cirrhotic population. Since the subdivision of culture positive and culture negative SBP is of limited interest in clinical practice, as the diagnosis of ascetic fluid infection is based on a neutrophil count > 250/mm3 [1] we combined culture-positive SBP and culture-negative SBP subgroups and as a result we have shown that serum procalcitonin was significantly increased in patients with in total SBP compared to sterile ascites with a high sensitivity (0.780) and specificity (0.750) for a AUC value of 0.824 which was better than CRP (AUC: $0.622, \mathrm{p}<0.004)$.

In terms of the value of procalcitonin in predicting infection, studies conducted in cirrhotic patients with bacterial peritonitis yielded conflicting results. Viallon et al. [15] compared 21 patients with bacterial peritonitis and 40 patients with sterile ascitic fluid and concluded that serum procalcitonin levels may be useful as a marker for the diagnosis of bacterial peritonitis in patients with cirrhosis. Spahr et al. [21] concluded, on the basis of their findings in a series of 10 patients with bacterial peritonitis and 10 with sterile ascites, that procalcitonin levels are inaccurate in the- se patients. While Bota et al. [31] reported that procalcitonin performed equally well for different types of infection in patients with and without cirrhosis in a study conducted with 864 patients, 79 (9\%) of whom had hepatic cirrhosis.

In our study population in cirrhotic patients, alike to findings of Viallon et al. [15] but opposing the study by Spahr et al. [21] procalcitonin levels were significant in identifying ascitic fluid culture positivity $(p<0.001)$ compared to negativity while SBP $(p<0.001)$, culture-negative SBP $(p=0.001)$ and bacterascites $(p=0.019)$ compared to sterile ascites. Besides, in contrast to findings of Bota et al. [31], procalcitonin levels were not significant in identifying infection in non-cirrhotic patients with malignant ascites despite mean ascitic fluid WBC count of $2685(417.0) / \mathrm{mm}^{3}$ and positive culture in $15.4 \%$ of patients in this group.

Given that clinical judgment does not rule out SBP and thus a diagnostic paracentesis should be performed in all patients with cirrhosis and ascites at hospital admission and/or in case of gastrointestinal bleeding, shock signs of inflammation, worsening of liver/renal function or hepatic encephalopathy [3], rapid detection and identification of bacteria in the ascitic fluid is the key to improve the survival of cirrhotic patients with ascitic fluid infection [7]. In this regard, based on easy to apply, rapid and cost-effective features, determination of serum procalcitonin levels seems to play an increasingly important role in the rapid detection and identification of cirrhosis related ascitic fluid infection, SBP in particular, for prompt initiation of appropriate therapy that might be helpful increasing overall survival of patients at high risk of SBP development [7].

In conclusion, according to our findings determination of serum procalcitonin levels seems to provide satisfactory diagnostic accuracy in differentiating bacterial infections in hospitalized patients with all-cause liver cirrhosis while not in non-cirrhotic malignancy related ascites with suggestion of a cut-off value of 0.61 for culture-positive SBP, $0.225 \mathrm{ng} / \mathrm{mL}$ for culture-negative SBP, $1.12 \mathrm{ng} / \mathrm{mL}$ for bacterascites and $0.42 \mathrm{ng} / \mathrm{mL}$ for patients who have either culture-positive SBP or culture-negative SBP (combination group) for clinical use. Given that performing ascitic fluid culture examination is time consuming and not always available in the emergency setting, high procalcitonin levels should be considered in combination with high PMNL in the differential diagnosis of patients with ascites. Further large-scale studies are needed to confirm the predictive role of serum procalcitonin levels in cirrhotic and non-cirrhotic in addition to identify more specific markers to predict diagnosis as well as prognosis in 
patients with ascites.

\section{Competing Interests}

The authors have declared that no competing interest exists.

\section{References}

1. European Association for the Study of the Liver. EASL clinical practice guidelines on the management of ascites, spontaneous bacterial peritonitis, and hepatorenal syndrome in cirrhosis. J Hepatol. 2010; 53(3): 397-417.

2. Hoefs JC, Runyon BA. Spontaneous bacterial peritonitis. Dis Mon. 1985; 31(9): 1-48.

3. Wiest R, Krag A, Gerbes A. Spontaneous bacterial peritonitis: recent guidelines and beyond. Gut. 2012; 61: 297-310.

4. Runyon BA, Hoefs JC. Culture-negative neutrocytic ascites: a variant of spontaneous bacterial peritonitis. Hepatology. 1984; 4: 1209-1211.

5. Sheer TA, Runyon BA. Spontaneous bacterial peritonitis. Dig Dis. 2005; 23: 39-46.

6. Such J, Frances R, Munoz C, et al. Detection and identification of bacterial DNA in patients with cirrhosis and culture-negative, nonneutrocytic ascites. Hepatology. 2002; 36: 135-141.

7. Mostafa MS, El-Seidi EA, Kassem AM, et al. Detection of ascitic fluid infections in patients with liver cirrhosis and ascites. Arab J Gastroenterol. 2011; 12: 20-24.

8. Nousbaum JB, Cadranel JF, Nahon P, et al. Diagnostic accuracy of the Multistix 8 SG reagent strip in diagnosis of spontaneous bacterial peritonitis. Hepatology. 2007; 45: 1275-1281.

9. Evans LT, Kim WR, Poterucha JJ, et al. Spontaneous bacterial peritonitis in asymptomatic outpatients with cirrhotic ascites. Hepatology. 2003; 37: 897-901.

10. Runyon BA. Management of adult patients with ascites caused by cirrhosis. Hepatology 1998; 27: 264-272.

11. Toledo C, Salmeron JM, Rimola A, et al. Spontaneous bacterial peritonitis in cirrhosis: predictive factors of infection resolution and survival in patients treated with cefotaxime. Hepatology. 1993; 17: 251-257.

12. Fernandez J, Navasa M, Planas R, et al. Primary prophylaxis of spontaneous bacterial peritonitis delays hepatorenal syndrome and improves survival in cirrhosis. Gastroenterology. 2007; 133: 818-824.

13. Albillos A, Cuervas-Mons V, Millan I,et al. Ascitic fluid polymorphonuclear cell count and serum to ascites albumin gradient in the diagnosis of bacterial peritonitis. Gastroenterology. 1990; 98(1): 134-140.

14. Yang CY, Liaw YF, Chu CM, et al. White count, $\mathrm{pH}$ and lactate in ascites in the diagnosis of spontaneous bacterial peritonitis. Hepatology. 1985; 5(1): 85-90.

15. Viallon A, Zeni F, Pouzet V, et al. Serum and ascitic procalcitonin levels in cirrhotic patients with spontaneous bacterial peritonitis: diagnostic value and relationship to pro-inflammatory cytokines. Intensive Care Med, 2000; 26: 1082-1088.

16. Dandona P, Nix D, Wilson MF, et al. Procalcitonin increase after endotoxin injection in normal subjects. J Clin Endocrinol Metab. 1994; 79( 6): 1605-1068.

17. Gendrel D, Bohuon C. Procalcitonin as a marker of bacterial infection. Pediatr Infect Dis J. 2000; 19: 679-687.

18. Rau B, Steinbach G, Gansauge F, et al. The potential role of procalcitonin and interleukin 8 in the prediction of infected necrosis in acute pancreatitis. Gut. 1997; 41: 832-840.

19. Geppert A, Steiner A, Delle-Karth G, et al. Usefulness of procalcitonin for diagnosing complicating sepsis in patients with cardiogenic shock. Intensive Care Med. 2003; 29: 1384-1389.

20. Wagner FD, Jonitz B, Potapov EV, et al. Procalcitonin, a donor-specific predictor of early graft failure-related mortality after heart transplantation. Circulation. 2001; 104: I192-I196.

21. Spahr L, Morard I, Hadengue A, et al. Procalcitonin is not an accurate marker of spontaneous bacterial peritonitis in patients with cirrhosis. Hepatogastroenterology. 2001; 48: 502-505.

22. Perumalswami PV, Schiano TD. The management of hospitalized patients with cirrhosis: the Mount Sinai experience and a guide for hospitalists. Dig Dis Sci. 2011; 56(5): 1266-1281.

23. Kim SU, Kim do Y, Lee CK, et al. Ascitic fluid infection in patients with hepatitis B virus-related liver cirrhosis: culture-negative culture-negative SBP versus spontaneous bacterial peritonitis. J Gastroenterol Hepatol. 2010; 25: 122-128.
24. Campillo B, Sherman E, Richardet JP, et al. Serum leptin levels in alcoholic liver cirrhosis: relationship with gender, nutritional status, liver function and energy metabolism. Eur J Clin Nutr. 2001; 55: 980-988.

25. Taneja SK, Dhiman RK. Prevention and management of bacterial infections in cirrhosis. Int J Hepatol. 2011; 2011: 784540.

26. Kamani L, Mumtaz K, Ahmed US, et al. Outcomes in culture positive, culture negative ascitic fluid infection in patients with viral cirrhosis: Cohort study. BMC Gastroenterol. 2008; 8: 59.

27. Pelletier G, Salmon D, Ink O, et al. Culture-negative neutrocytic ascites: a less severe variant of spontaneous bacterial peritonitis. J Hepatol. 1990; 10: 327-331

28. Al Amri SM, Allam AR, Al Mofleh IA. Spontaneous bacterial peritonitis and culture negative culture-negative SBP in patients with non-alcoholic liver cirrhosis. J Gastroenterol Hepatol. 1994; 9(5): 433-436.

29. Zou MX, Zhou RR, Wu WJ, et al. The use of pleural fluid procalcitonin and C-reactive protein in the diagnosis of parapneumonic pleural effusions: a systemic review and meta-analysis. Am J Emerg Med. 2012; 30(9):1907-1914.

30. Fernández J, Gustot T. Management of bacterial infections in cirrhosis. J Hepatol. 2012; 56 (Suppl 1): S1-12.

31. Bota DP, Van Nuffelen M, Zakariah A, et al. Serum levels of C-reactive protein and procalcitonin in critically ill patients with cirrhosis of the liver. J Lab Clin Med. 2005; 146: 347-351. 